\title{
Atmospheric Pressure MALDI-FTMS of Normal and Chemically Modified RNA
}

\author{
Katherine A. Kellersberger, Eizadora T. Yu, Samuel I. Merenbloom, \\ and Daniele Fabris \\ University of Maryland, Baltimore Country, Baltimore, Maryland, USA
}

\begin{abstract}
Atmospheric pressure (AP) MALDI has been combined with Fourier transform mass spectrometry (FTMS) to obtain the unambiguous characterization of RNA samples modified by solvent accessibility reagents used in structural studies of RNA and protein-RNA complexes. The formation of cation adducts typical of MS analysis of nucleic acids was effectively reduced by extensive washing of the anionic analytes retained onto the probe surface by strong interactions with a cationic layer of poly(diallyldimethylammonium chloride) (PADMAC). This rapid desalting procedure allowed for the detection of DNA and RNA samples in high femtomole quantities distributed over a $4 \times 4 \mathrm{~mm}$ sample well. AP MALDI-FTMS was shown to provide high-resolution spectra for analytes as large as $\sim 6.4 \mathrm{kDa}$ with little or no evidence of metastable decomposition. The absence of significant metastable decay observed for precursor ions selected for tandem experiments offered a further measure of the low energy content typical of ions generated by AP MALDI. This feature proved to be very beneficial in the characterization of chemically modified RNA samples, which become particularly prone to base losses upon alkylation. The high resolution offered by FTMS enabled the application of a data-reduction algorithm capable of rejecting any signal devoid of plausible isotopic distribution, thus facilitating the analysis of complex analyte mixtures produced by nuclease treatment of RNA substrates. Proper selection of nucleases and digestion conditions can ensure the production of hydrolytic fragments of manageable size, which could extend the range of applicability of this bottom-up strategy to the structural investigation of very large RNA and protein-RNA complexes. (J Am Soc Mass Spectrom 2005, 16, 199-207) (C 2004 American Society for Mass Spectrometry
\end{abstract}

$\mathrm{T}$ The analysis of nucleic acids by matrix-assisted laser desorption ionization (MALDI) [1, 2] mass spectrometry has to contend with the intrinsic fragility of their respective pseudo-molecular ions, which are prone to extensive gas-phase decomposition in the source region and in the mass analyzer [3-8]. The prompt fragmentation and metastable decay of these ions are only desirable when the ultimate goal is to obtain sequence information on normal and modified nucleic acids [3, 5, 9-12]. Far more frequently, these processes result in unwanted loss of sensitivity and resolution, which may severely hamper the detection of the analyte of interest. The occurrence and extent of decomposition have been correlated not only to the laser energy, the choice of matrix, and the sample base composition [13-15], but also to the time necessary to complete the mass analysis. In general, nucleic acid ions are known to undergo more extensive metastable decay when analyzed by Fourier transform mass spectrometry (FTMS) $[16,17]$ than by time-of-flight (TOF) $[18,19]$,

Published online December 16, 2004

Address reprint requests to Dr. D. Fabris, Department of Chemistry and Biochemistry, University of Maryland, Baltimore County, 1000 Hilltop Circle, Baltimore, MD 21250, USA. E-mail: fabris@umbc.edu as expected from the substantially longer time scale associated with the former than with the latter technique (i.e., in the order of milliseconds to seconds versus microseconds) [3, 9, 20-22].

Over the years, the potential of MALDI-FTMS for high-resolution analysis of biomolecules has provided a powerful motivation for the development of strategies aimed at minimizing gas-phase decomposition and improving sensitivity and resolution. The utilization of selected matrix additives, refined trapping and axialization methods, and collisional cooling of trapped ions was initially proposed to increase the performance of instruments in which ions were generated within the FTMS cell, or in its immediate proximity [23-31]. Later, the introduction of external MALDI sources enabled the decoupling of the ion production from the analysis step and afforded a more efficient way to control the cell vacuum through multiple stages of differential pumping [32-34]. This feature has gained further significance since the more recent demonstration that low-energy ions could be effectively produced by injecting inert gas into the external source during the desorption event [35-37], in agreement with initial results obtained on a MALDI-TOF instrument [38].

The concept of collisional dampening of MALDI- 
generated ions has been taken a step further by the parallel development of atmospheric pressure (AP) MALDI $[39,40]$, in which ions are produced by firing a laser at a sample plate that is held very close to the inlet of an atmospheric pressure ionization (API) source. In this case, the plume is drawn into the source by pressure and voltage gradients, while ions undergo collisional cooling and declustering processes that are similar in nature to those involved with desolvation in electrospray ionization (ESI) [41].

Implemented on quadrupole-time-of-flight $[40,42$, 43] and ion trap [44-48] analyzers, AP MALDI has proven to be very effective in the analysis of labile post-translational modifications [46, 49, 50], oligosaccharides [51], and lipopeptides [52]. We have recently investigated the merits of coupling this ionization technique with FTMS for the characterization of complex peptide mixtures, demonstrating the ability to fully resolve isobaric peptides that differ in mass by less than $0.04 \mathrm{Da}$ [53]. The aim of the present work is to assess the value of AP MALDI-FTMS in the investigation of normal and chemically modified nucleic acids. In particular, we have tested the hypothesis that the gentle nature of this ionization technique may facilitate the characterization of analytes that are very fragile per se and become increasingly prone to gas-phase fragmentation upon covalent modification of the nucleobases.

\section{Experimental}

RNA constructs were prepared by in vitro transcription of synthetic DNA templates using the phage T7 polymerase, or purchased from Dharmacon Research, Inc. (La Fayette, CO). DNA templates, primers, and standards were purchased from the W. M. Keck Foundation Biotechnology Resource Laboratory at Yale University (New Haven, CT). The solvent accessibility probes dimethylsulfate (DMS) and 1-cyclohexyl-3-(2-morpholinoethyl)-carbodiimide metho- $p$-toluene sulfonate (CMCT) were purchased from Sigma-Aldrich Chemical Co. (St. Louis, MO), while kethoxal (KT) was obtained from ICN Biomedicals, Inc. (Costa Mesa, CA). MALDI matrices $\alpha$-cyano-4-hydroxycinnamic acid (CHCA), 2-(4-hydroxyphenylazo)benzoic acid (HABA), nicotinic acid (NA), 3-hydroxypicolinic acid (3-HPA), and sinapinic acid (SA) were purchased from Sigma-Aldrich Chemical Co. (St. Louis, MO). Saturated solutions were prepared immediately prior to analysis using HPLCgrade acetonitrile and deionized water. Poly(diallyldimethylammonium chloride) (PADMAC) was purchased from Polysciences, Inc. (Warrington, PA). All reagents were used as received from the manufacturer without further purification.

After heat renaturation of the RNA constructs, $10 \mu \mathrm{L}$ of up to $20 \mu \mathrm{M}$ solutions of substrate were treated with the chemical probes as described earlier [54]. Alkylated products and un-modified controls were subsequently digested with either RNase A or T1 (Sigma-Aldrich
Chemical Co.), and desalted by overnight ethanol precipitation [54]. The pellets were redissolved with $\sim 10 \mu \mathrm{L}$ of $10 \mathrm{mM}$ ammonium acetate (pH 7.0) immediately prior to analysis.

Each well on the sample stage was initially treated by depositing $1 \mu \mathrm{L}$ of a $100 \mathrm{mg} / \mathrm{mL}$ PADMAC solution in water. After washing the excess solution from the PADMAC layer formed on the metal surface, $\sim 1.0 \mu \mathrm{L}$ of up to $20 \mu \mathrm{M}$ solutions in total RNA (unless otherwise indicated) was typically spotted onto each well and incubated for $15 \mathrm{~min}$ at room temperature to allow for binding of oligonucleotide analytes to the polycationic coating. The binding procedure was followed by at least four consecutive washes using $2 \mu \mathrm{L}$ each of a $10 \mathrm{mg} / \mathrm{mL}$ solution of ammonium citrate in water. Finally, $1.0-2.0 \mu \mathrm{L}$ of saturated matrix solution was applied and let dry at room temperature.

All samples were analyzed on a Bruker (Billerica, MA) Apex III Fourier transform mass spectrometer equipped with a 7.0 tesla superconducting magnet and an Apollo atmospheric pressure ionization interface, which was fitted with a MassTech (Columbia, MD) AP/MALDI source model 221 described previously $[53,55,56]$. The source consists of a flange containing a computer-controlled $\mathrm{X}-\mathrm{Y}$ positioning stage and a digital camera, and is powered by a control unit that includes a commercial nitrogen laser $(337 \mathrm{~nm})$. Upon laser firing, photons are transmitted from the control unit to the flange by an optical fiber cable (400 $\mu \mathrm{m}$ diameter). The sample position can be controlled either manually by the user or set to raster automatically through the sample well according to predefined patterns (Target software, MassTech, Inc.). A recently developed pulsed dynamic focusing (PDF) [57] module can be tuned to momentarily switch off the high voltage $(2.5-3.5 \mathrm{kV})$ applied between the sample plate and the API inlet, in such a way as to allow for the majority of ions to be efficiently entrained by the pressure gradient between the atmospheric region and the first stage of vacuum, rather than follow the field lines and discharge on the inlet sides or the source walls [53,57]. No drying gas was employed in these experiments; a range of capillary temperatures $\left(\mathrm{T}_{\mathrm{C}}\right)$ was varied between 150 and $240{ }^{\circ} \mathrm{C}$.

Typical spectra were the result of an average of 5-200 scans acquired in positive ion mode with a total accumulation time varying from 12.5 to $400 \mathrm{~s}$, during which the laser was continuously fired with a $10 \mathrm{~Hz}$ repetition rate. The time allowed for ions to accumulate in the external hexapole, which is located immediately after the second skimmer in the API source [58], was largely responsible for determining the total duration of each scan. Tandem experiments were carried out by isolating the precursor ion of interest using correlated RF sweeps $(\mathrm{CHEF})^{\circ}[59]^{\circ}$ followed ${ }^{\circ}$ by $^{\circ}$ activation $^{\circ}$ through $^{\circ}$ sustained off-resonance $^{\circ}$ irradiation $^{\circ}(\mathrm{SORI})^{\circ}[60]^{\circ}$ against $^{\circ}$ an $^{\circ} \mathrm{Ar}$ background. Irradiation frequencies that were both above and below the cyclotron frequency of the precur- 
sor ion were tested to avoid the occurrence of blind spots $^{\circ}$ in $^{\circ}$ the $^{\circ}$ product $^{\circ}$ ion $^{\circ}$ spectrum $^{\circ}[60] . .^{\circ}$ Optimal ${ }^{\circ}$ frequency offsets were found to be $\sim 400-2000 \mathrm{~Hz}$ below that of the precursor ion. Mass assignments were based on a minimum three point external calibration obtained from standard oligonucleotides.

\section{Results and Discussion}

Sample preparation constitutes a crucial aspect in MALDI analysis of nucleic acids, which are prone to formation of cation adducts that may induce loss of resolution ${ }^{\circ}$ and $^{\circ}$ signal $^{\circ}$ suppression $^{\circ}[5] .{ }^{\circ} \mathrm{A}^{\circ}$ valid $^{\circ}$ alternative to lengthy purification procedures involving ultrafiltration or HPLC is provided by on-probe desalting strategies, which take advantage of the strong electrostatic interactions between negatively charged oligonucleotides and polycationic films deposited ${ }^{\circ}$ onto ${ }^{\circ}$ the ${ }^{\circ}$ MALDI $^{\circ}$ stage $\left.95,61-63\right] .{ }^{\circ}$ Following ${ }^{\circ} a$ similar approach, we have implemented an on-probe purification protocol, which uses sample wells coated by an homogeneous layer of poly(diallyldimethylammonium chloride) (PADMAC, see the Experimental section) to selectively retain oligonucleotide samples over salt interferents and allow for their extensive washing with ammonium citrate before matrix application $^{\circ}[64] .{ }^{\circ}$ As $^{\circ}$ shown $^{\circ}$ in $^{\circ}$ Figure $^{\circ} 1,^{\circ}$ the $^{\circ}$ capture / washing procedure was found to be critical for the detection of DNA and RNA oligonucleotides by AP MALDI-FTMS. Possibly attributable to overwhelming suppression effects, no signal could be detected for a standard 7-mer deoxyoligonucleotide (QZ11, sequence $^{\circ}$ provided $^{\circ}$ in $^{\circ}$ Table $^{\circ} 1$ ), ${ }^{\circ}$ which $^{\circ}$ was $^{\circ}$ loaded onto untreated sample plates and immediately analyzed $^{\circ}\left(\right.$ Figure $\left.^{\circ} 1 \mathrm{a}\right) .{ }^{\circ} \mathrm{On}^{\circ}$ the $^{\circ}$ contrary, $^{\circ}$ intense ${ }^{\circ}$ signals were readily observed upon capture and desalting on PADMAC-coated $^{\circ}$ wells $^{\circ}\left(\right.$ Figure $\left.^{\circ} 1 b-\mathrm{d}\right)$.

Classic MALDI matrices recommended for nucleic acids, such as nicotinic acid (NA) and 3-hydroxypico-

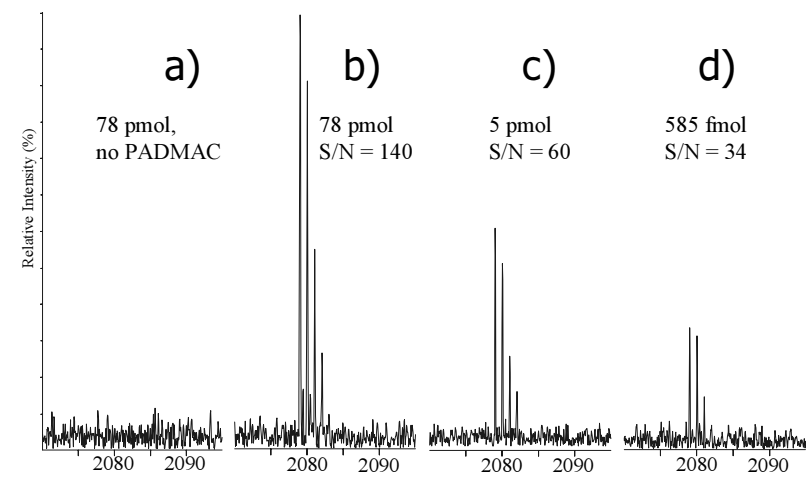

Figure 1. AP MALDI-FTMS analysis of the standard 7 mer deoxy-oligonucleotide QZ11 (see Table 1) using $\alpha$-cyano-4hydroxycinnamic acid (CHCA) in positive ion mode: (a) 78 pmol loaded on the probe and analyzed directly; (b) 78 pmol submitted to on-probe purification (see Experimental); (c) 5 pmol with onprobe purification; (d) $585 \mathrm{fmol}$ with on-probe purification. Only the region including the singly protonated ion is shown.
Table 1. Summary of standard DNA and RNA samples employed in this study

\begin{tabular}{|c|c|c|}
\hline Name & Sequence & $\begin{array}{c}\text { Calc. } \\
\text { monoisotopic } \\
\text { mass (Da) }\end{array}$ \\
\hline AA & $A A^{a}$ & 564.16 \\
\hline TT & $\mathrm{TT}^{\mathrm{a}}$ & 546.14 \\
\hline AG & $A G^{b}$ & 612.14 \\
\hline $\mathrm{G}_{4}$ & $\mathrm{GGG} \mathrm{G}^{\mathrm{a}}$ & 1254.25 \\
\hline QZ11 & ATC GAT C ${ }^{a}$ & 2079.39 \\
\hline $\mathrm{U}_{10}$ & $(U)_{10}^{b}$ & 2998.29 \\
\hline $\mathrm{T}_{10}$ & $(\mathrm{~T})_{10}{ }^{\mathrm{a}}$ & 2978.50 \\
\hline D10 & ATC GGC CAC $A^{a}$ & 2995.55 \\
\hline D12 & CAG TCA GCT CAG ${ }^{a}$ & 3628.65 \\
\hline $\mathrm{U}_{20}$ & $(U)_{20}^{b}$ & 6018.96 \\
\hline $\mathrm{T}_{20}$ & $(T)_{20}{ }^{a}$ & 6058.54 \\
\hline QZ2 & TAT TGC TTT AAA AAC TCA AAA & 6393.10 \\
\hline QZ1 & TTT TGA GTT TTT AAA GCA ATA & 6446.13 \\
\hline
\end{tabular}

a Oligodeoxyribonucleotides.

boligoribonucleotides.

linic acid (3-HPA), were initially tested, as well as matrices that are traditionally considered more suitable for proteins and peptides, such as $\alpha$-cyano-4-hydroxycinnamic acid (CHCA), 2-(4-hydroxyphenylazo)benzoic acid (HABA), and sinapinic acid (SA). Using CHCA, which produced the best results in positive ion mode, a practical sensitivity limit of 585 fmol initially loaded onto the well was determined for the entire analytical procedure, which provided a signal-to-noise ratio $(\mathrm{S} / \mathrm{N})$ of $34: 1$ for the standard heptamer QZ11

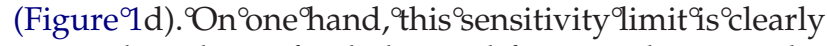
worse than the $10 \mathrm{fmol}$ obtained for peptides in analogous AP MALDI-FTMS experiments using the same matrix $^{\circ}[53]^{\circ}$, confirming $^{\circ} \mathrm{a}^{\circ}$ general $^{\circ}$ trend $^{\circ}$ in $^{\circ}$ MALDI analyses that report better results for peptides than for oligonucleotides. On the other hand, this figure of merit appears to be at least comparable to the 1 pmol limit observed with a 20:1 S/N for a 20-mer deoxyoligonucleotide analyzed on a vacuum MALDI-FTMS with external source, although a proper comparison is made problematic by the size disparity, which tends to favor the smaller oligonucleotide, and by the absence of on-probe ${ }^{\circ}$ purification $^{\circ}$ for $^{\circ}$ the $^{\circ} 20$-mer $^{\circ}$ sample $^{\circ}$ [22].$^{\circ}$ In fairness, it should be mentioned that, during the capture process, the nucleic acid samples were allowed to freely distribute over the entire surface of each sample well coated by PADMAC, which corresponds to a $4 \times 4$ $\mathrm{mm}$ area carved onto the gold plate. Considering the tightly focused laser beam ( $\sim 200 \mu \mathrm{m}$ diameter $)$ used to raster across the well, only a small portion of total analyte was actually consumed during a typical AP MALDI analysis. Therefore, much lower detection limits could be potentially reached through the implementation ${ }^{\circ}$ of $^{\circ}$ micro-spotting ${ }^{\circ}[65]^{\circ}$ or $^{\circ}$ patterned ${ }^{\circ}$ monolayer $[66]^{\circ}$ techniques $^{\circ}$ developed $^{\circ}$ for $^{\circ}$ vacuum $^{\circ}$ MALDI-TOF. The fact that the S/N observed for QZ11 does not appear to decrease linearly with the initial amount loaded ${ }^{\circ}$ onto $^{\circ}$ each $^{\circ} \operatorname{spot}^{\circ}\left(\text { Figure }^{\circ} 1 b-\mathrm{d}\right)^{\circ} \operatorname{cannot}^{\circ}$ be $^{\circ}$ attrib- 


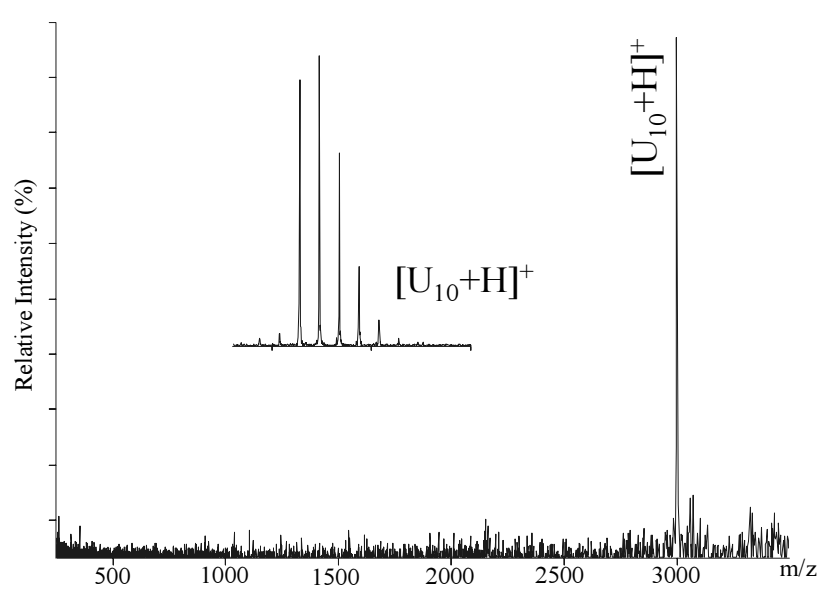

Figure 2. Analysis of standard 10-mer uridine $\left(\mathrm{U}_{10}\right)$ provided an experimental mass of $2998.328 \mathrm{Da}$ (2998.294 Da calculated from sequence) and an accuracy of $\sim 8 \mathrm{ppm}$. An initial amount of $\sim 10$ pmol was submitted to on-probe purification. CHCA was used as matrix in positive ion mode. The isotopic distribution shown in the inset enabled to calculate a resolving power of $\sim 90,000 \mathrm{M} / \Delta \mathrm{M}_{\mathrm{fwhm}}$, obtained at $\sim 3000 \mathrm{~m} / \mathrm{z}$ in broadband mode.

uted solely to desorption effects, but could also be due to possible saturation of the PADMAC layer and subsequent sample loss during citrate washing. Further investigation will be necessary to elucidate the parameters affecting the on-probe protocol.

Optimization of the source parameters was carried out by weighing the incidence of possible metastable decomposition, which is a sign of excessive energy involved with the initial desorption event or with the declustering process in the API interface, against the abundance of matrix-analyte clusters that are typically observed when insufficient energy is available for declustering. Under optimal conditions, no significant metastable products could be observed in the AP MALDI-FTMS analysis of DNA and RNA oligonucleotides of very diverse sequence and base composition (summarized ${ }^{\circ}$ in $^{\circ}$ Table $^{\circ} 1$ ), ${ }^{\circ}$ as $^{\circ}$ exemplified ${ }^{\circ}$ by $^{\circ}$ the ${ }^{\circ}$ spectrum of uridine decamer $\left(\mathrm{U}_{10}\right)^{\circ}$ shown $^{\circ}$ in $^{\circ}$ Figure $^{\circ} 2 .{ }^{\circ}$ The formation of matrix-adducts was also found to be much less prominent than previously observed for peptide analytes ${ }^{\circ}$ under $^{\circ}$ similar $^{\circ}$ experimental ${ }^{\circ}$ conditions $^{\circ}[53]^{\circ} .^{\circ}$ In fact, no matrix-analyte clusters were detected for $\mathrm{U}_{10}$ by using a capillary temperature $\left(\mathrm{T}_{\mathrm{C}}\right)$ of $220^{\circ} \mathrm{C}$ and a $250 \mathrm{~V}$ difference in potential between the exit of the capillary and the first skimmer $\left(\Delta \mathrm{V}_{\mathrm{CS}}\right)$. By comparison, intense adducts were previously observed for melittin (a peptide of similar size, $\sim 2.9 \mathrm{kDa}$ ) using analogous instrumental parameters and matrix, thus suggesting a strong correlation of cluster formation with the analyte chemical nature rather than with its size, as previously suggested ${ }^{\circ}[53]$.

The monoisotopic mass provided by the singly charged ion of $\mathrm{U}_{10}$ matched very closely the mass calculated from sequence (2998.318 and 2998.294 Da, respectively), for an accuracy of $\sim 8 \mathrm{ppm}$. As determined from the isotopic distribution displayed by the inset InFigure2, 'typical'broadband analysisallowed for a resolving power of $\sim 90,000 \mathrm{M} / \Delta \mathrm{M}_{\mathrm{fwhm}}$ at $\sim 3000 \mathrm{~m} / \mathrm{z}$. While this figure of merit tends to progressively deteriorate at higher mass-over-charge ratios $(\mathrm{m} / \mathrm{z})$ regardless of how the ions of interest are actually produced [16], ${ }^{\circ}$ the ${ }^{\circ}$ isotopic ${ }^{\circ}$ distribution ${ }^{\circ}$ of $^{\circ}$ larger ${ }^{\circ}$ singly ${ }^{\circ}$ charged species could still be resolved, as demonstrated by the analysis of standard 21-mer deoxy-oligonucleotides $\left(\mathrm{QZ1}{ }^{\circ} \text { and }^{\circ} \mathrm{QZZ},{ }^{\circ} \mathrm{Table}^{\circ} 1\right)^{\circ} \mathrm{with}^{\circ}$ molecular ${ }^{\circ}$ masses ${ }^{\circ}$ falling in $^{\circ}$ the ${ }^{\circ} \sim 6400^{\circ} \mathrm{m} / \mathrm{z}$ range $^{\circ}\left(\text { Figure }^{\circ} 3\right)^{\circ} .^{\circ}$ In $^{\circ}$ this ${ }^{\circ}$ case, $^{\circ}$ the isotopic envelopes shown in the insets afforded an average resolving power of $\sim 26,000 \mathrm{M} / \Delta \mathrm{M}_{\mathrm{fwhm}}$, which enabled us to readily distinguish actual signals from RF spikes and background noise. It should be noted also that efficient desorption of progressively larger species required corresponding increases of laser irradiation (achieved by reducing the degree of attenuation applied by a filter to the original laser beam), which makes it more difficult to strike the correct energy balance necessary to provide sufficient ion currents without triggering metastable processes. It is not surprising that the best possible signal for the 21-mer QZ1 and QZ2 was obtained under instrumental conditions that also induced a detectable level of guanine loss from QZ1 (Figure 3 ).

For smaller analytes, however, the AP MALDI source was found to produce sufficient ion currents to perform tandem experiments without undue increases in $^{\circ}$ laser $^{\circ}$ irradiation. ${ }^{\circ}$ Figure ${ }^{\circ} 4^{\circ}$ shows $^{\circ}$ the $e^{\circ}$ isolation ${ }^{\circ}$ and product ion spectra obtained by submitting a 12 mer deoxyoligonucleotide (D12, sequence provided in Table 1$)^{\circ}$ to $^{\circ}$ sustained ${ }^{\circ}$ off-resonance irradiation ${ }^{\circ}$ collisioninduced $^{\circ}$ dissociation $^{\circ}(\text { SORI-CID })^{\circ}[60]^{\circ} .^{\circ}$ Consistent ${ }^{\circ}$ with the normally low energy content of ions generated by AP MALDI, no metastable decomposition could be

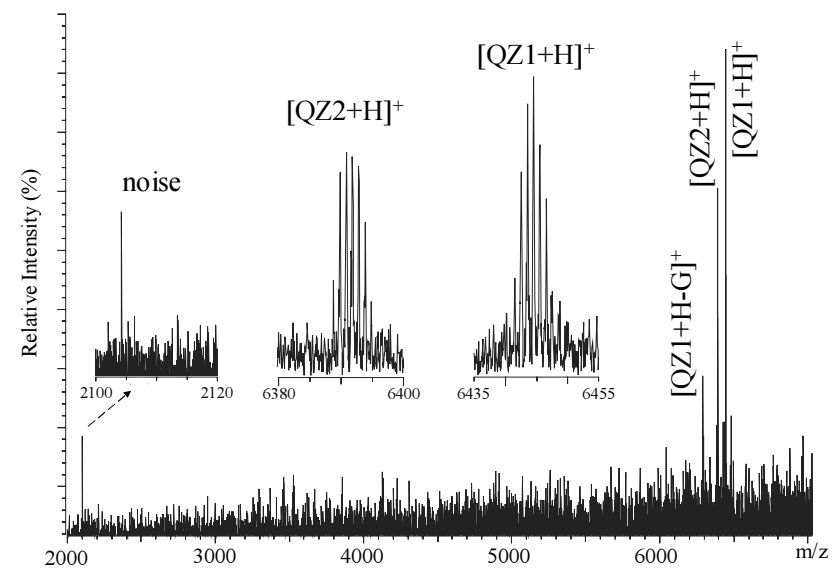

Figure 3. Analysis of two 21-mer deoxy-oligonucleotides QZ1 and ${ }^{\circ} \mathrm{QZ2}^{\circ}\left(\right.$ Table $\left.^{\circ} 1\right){ }^{\circ}{ }^{\circ}$ which $^{\circ}$ provided $^{\circ}$ observed ${ }^{\circ}$ masses $^{\circ}$ of ${ }^{\circ} 6445.930$ and 6392.953 Da corresponding, respectively, to monoisotopic 6446.111 and $6393.134 \mathrm{Da}$ calculated from sequence, for a $\sim 28 \mathrm{ppm}$ accuracy. An initial amount of $\sim 20$ pmol was submitted to on-probe purification. CHCA was used as matrix in positive ion mode. The isotopic distributions shown in the insets correspond to an average resolving power of $\sim 26,000 \mathrm{M} / \Delta \mathrm{M}_{\mathrm{fwhm}}$ at $\sim 6400 \mathrm{~m} / \mathrm{z}$ in broadband mode. 


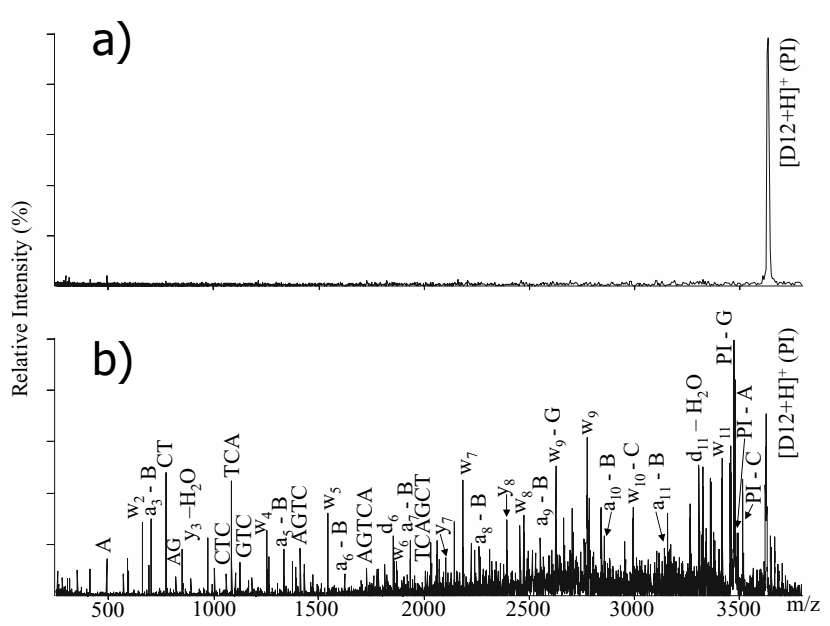

Figure 4. Isolation spectrum (a) and sustained off-resonance irradiation collision-induced dissociation (SORI-CID) product ion spectrum $^{\circ}(\mathbf{b})^{\circ}$ obtained $^{\circ}$ from $^{\circ}$ singly ${ }^{\circ}$ charged $^{\circ}$ D $12^{\circ}\left(\right.$ Table $\left.^{\circ} 1\right) .^{\circ}$ An initial amount of $\sim 45$ pmol was submitted to on-probe purification. CHCA was used as matrix in positive ion mode. No metastable decomposition could be observed after trapping the precursor ion for up to 5 s. P.I. indicates the precursor ion observed at $3628.65 \mathrm{~m} / \mathrm{z}$.

observed in the isolation spectrum, even after extended trapping (up to $\sim 5 \mathrm{~s}$ ) and despite the intrinsic fragility of ${ }^{\circ}$ nucleic ${ }^{\circ}$ acids ${ }^{\circ}$ ions ${ }^{\circ}[5]^{\circ}\left({ }^{\circ}\right.$ Figure $\left.^{\circ} 4 a\right) .{ }^{\circ}$ Subsequent ${ }^{\circ}$ collisional activation provided characteristic series of product ions, which properly matched the analyte sequence (Figure ${ }^{\circ} 4 \mathrm{~b}$ )..$^{\circ}{ }^{\circ}{ }^{\circ}$ ppite $^{\circ}$ of ${ }^{\circ}$ the ${ }^{\circ}$ fact ${ }^{\circ}$ that ${ }^{\circ}$ singly ${ }^{\circ}$ charged ${ }^{\circ}$ ions of relatively large species tend to produce less extensive fragmentation than the corresponding multiply charged ions under normal CID conditions, the products obtained from collisional activation of D12 at $\mathrm{m} / \mathrm{z} 3628.65$ allowed for nearly complete sequence coverage.

The experimental conditions optimized using standard oligonucleotides were readily applied to the characterization of alkylated RNA products obtained by treating complex RNA structures with solvent accessibility probes. This application draws its significance from the fact that stable secondary and tertiary structures, ${ }^{\circ}$ such $^{\circ}$ as $^{\circ}$ stem-loop hairpins ${ }^{\circ}$ and $^{\circ}$ pseudoknots $[$ [67], are precisely defined by the location of single- versus double-stranded regions, which can be efficiently revealed by alkylation with specific chemical probes. In previous work, we proposed a strategy based on sol- vent accessibility probes, such as dimethylsulfate (DMS), kethoxal (KT), and 1-cyclohexyl-3-(2-morpholinoethyl)carbodiimide metho- $p$-toluenesulfonate (CMCT), which form covalent adducts with nucleotides that are not base-paired or otherwise protected (with DMS alkylating N7 of G, N1 of A, and N3 of C; KT modifying $\mathrm{N} 1$ and N2 of G; CMCT alkylating N1 of G and N3 of U) [54]..$^{\circ} \mathrm{We}^{\circ}$ have $^{\circ}$ now $^{\circ}$ tested ${ }^{\circ}$ the ${ }^{\circ}$ ability ${ }^{\circ}$ of $^{\circ} \mathrm{AP}^{\circ} \mathrm{MALDI}-$ FTMS to reveal the position of probed nucleotides by mapping the products of nuclease digestion performed before and after application of chemical probes to complex RNA substrates, such as the ribosomal frameshifting pseudoknot of the mouse mammary tumor virus (VPK), the feline immunodeficiency virus pseudoknot (FIV-PK), and the human immunodeficiency $^{\circ}$ virus ${ }^{\circ}$ Type $^{\circ}{ }^{\circ}$ packaging $^{\circ}$ signal $^{\circ}\left(\mathrm{HIV}-1^{\circ} \mathrm{Psi}\right)^{\circ}$ (Table 2). ${ }^{\circ}$ Representative ${ }^{\circ}$ spectra ${ }^{\circ}{ }^{\circ}{ }^{\circ}$ shown ${ }^{\circ}$ in ${ }^{\circ}$ Figure ${ }^{\circ} 5^{\circ}$ for ${ }^{\circ}$ the RNase A digest of VPK before and after probing with $\mathrm{CMCT}$, which provided an $\sim 86 \%$ coverage of the pseudoknot sequence. Matching the masses of the species detected in the control experiment with those predicted from the sequence enabled the immediate identification of the sites susceptible to nuclease cleavage under the selected experimental conditions ( marked $^{\circ}{ }^{\circ}{ }^{\circ}$ dashed $^{\circ}$ lines $^{\circ}$ on $^{\circ}$ the $^{\circ}$ structure ${ }^{\circ}$ in ${ }^{\circ}$ Figure ${ }^{\circ} 5$ ). Similarly, the presence of chemical modification was unambiguously revealed by the characteristic mass shift (251.30 Da) induced by reaction of CMCT with exposed nucleotides ${ }^{\circ}$ during $^{\circ}$ the ${ }^{\circ}$ probing $^{\circ}$ procedure $^{\circ}\left(\right.$ Figure $\left.^{\circ} 5 b\right)$ [54].

Possible concerns about the practical mass range of AP MALDI-FTMS can be addressed by considering that all the hydrolysis products predicted from the substrate sequences ${ }^{\circ}$ and ${ }^{\circ}$ the ${ }^{\circ}$ nuclease ${ }^{\circ}$ specificity $^{\circ}\left(\right.$ Table $^{\circ}$ 2) ${ }^{\circ}$ appear to fall well within the practical upper $\mathrm{m} / \mathrm{z}$ limit determined by our standard oligonucleotides $(\sim 6400 \mathrm{~m} / \mathrm{z})$, assuming that each susceptible site is efficiently cleaved by RNase A and T1. While in some cases it was actually possible to detect the heaviest predicted species, this was not realized in all of the nuclease mixtures analyzed $^{\circ}\left(\right.$ Table $\left.^{\circ} 2\right) .^{\circ}$ This $^{\circ}$ observation ${ }^{\circ}$ could $^{\circ}$ be $^{\circ}$ partially justified by the fact that no attempt was made to increase the desorption of larger ions by further increasing the laser irradiation, for fear of activating unwanted base losses through metastable processes, which were normally absent under the selected experimental con-

Table 2. Summary of RNA substrates submitted to chemical probing and analyzed according to a bottom-up strategy based on digestion by RNase A and T1, and mass mapping by AP MALDI- FTMS. All values correspond to monoisotopic masses

\begin{tabular}{llccc}
\hline Substrate & & VPK & FIV-PK & HIV-1 Psi \\
\hline \hline Size (nucleotides) & & 34 & 35 & 118 \\
Mass (Da, from sequence) & & 11170.43 & 11314.59 & 38863.15 \\
Predicted number of hydrolysis products & RNase A & 15 & 14 & 40 \\
& RNase T1 & 11 & 13 & 51 \\
Predicted mass range of hydrolysis products & RNase A & $323.05-2329.35$ & $323.05-1703.24$ & $323.05-4697.68$ \\
& RNase T1 & $363.05-4145.57$ & $363.05-2925.41$ & $363.05-3842.50$ \\
Heaviest hydrolysis product detected & RNase A & 2329.40 & n/a & 1969.46 \\
& RNase T1 & 1833.29 & 2925.40 & 1632.23 \\
\hline
\end{tabular}



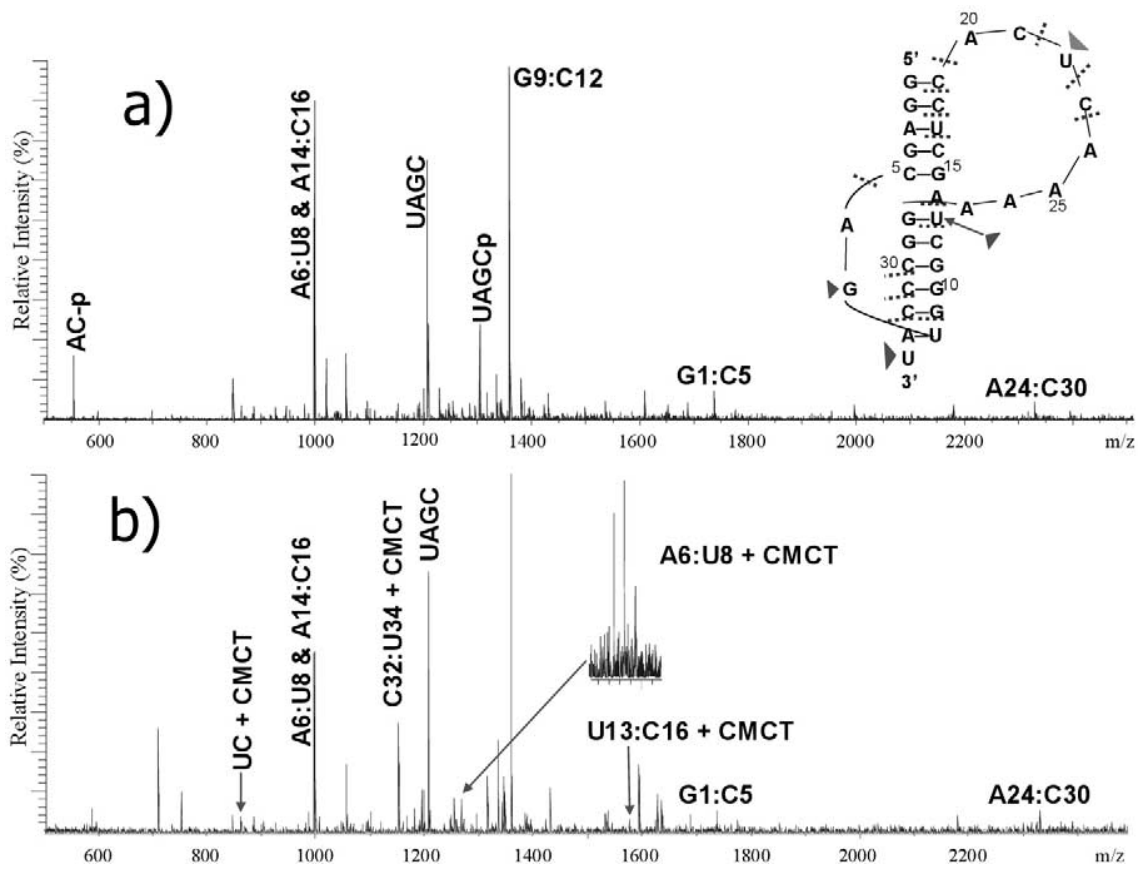

Figure 5. Nuclease mapping of mouse mammary tumor virus pseudoknot (VPK) before (a) and after (b) probing with 1-cyclohexyl-3-(2-morpholinoethyl)carbodiimide metho- $p$-toluenesulfonate (CMCT)

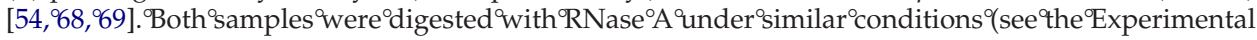
section). An initial amount of $\sim 20 \mathrm{pmol}$ in total RNA was submitted to on-probe purification. CHCA was used as matrix in positive ion mode. The cleavage products are labeled using the first and last nucleotides separated by a colon. Phosphate groups are indicated by p. Cleavage sites are reported as dashed lines on the pseudoknot structure, while the alkylated bases are identified by solid triangles. All detected signals corresponded to singly protonated ions.

ditions. It is also possible that the on-probe capture/ desalting procedure or the AP MALDI desorption itself may discriminate against the larger ions, when these are submitted as part of complex sample mixtures. Fortunately, the application of at least two different nucleases can usually provide overlapping sets of products, which cover the whole span of the initial structure of interest and enable the completion of a full protection map without requiring the detection of all predicted hydrolysis products.

Finally, the high resolution achieved in these experiments proved to greatly facilitate the interpretation of the very crowded spectra obtained from digest mixtures of probed substrates. In particular, high resolution allowed for the application of a recently developed algorithm designed to filter out signals that do not possess $^{\circ}$ proper $^{\circ}$ isotopic ${ }^{\circ}$ distributions ${ }^{\circ}(\text { MS2Links) })^{\circ}[68]$. In this way, weaker signals that could be easily overlooked by visual inspection are instead readily discriminated $^{\circ}$ from $^{\circ}$ background $^{\circ}$ noise ${ }^{\circ}$ (Figure ${ }^{\circ} 5 b^{\circ}$ inset $^{\circ}$ and

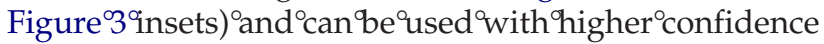
to compile more informative protection maps and generate ${ }^{\circ}{ }^{\circ}{ }^{\circ}{ }^{\circ}$ quality $^{\circ} 3-\mathrm{D}^{\circ}$ models $^{\circ}[69]$.

\section{Conclusions}

The features and figures of merit offered by $\mathrm{AP}$ MALDI-FTMS make this technique well suited for the characterization of sample mixtures produced by chemical probing and nuclease digestion of complex RNA structures. Under optimal conditions, the nearly complete absence of base loss and backbone fragmentation due to gas-phase metastable processes allows for the observation of intact adducts, which preserve the structural information stored by the solvent accessibility probes. The high resolution afforded by FTMS analysis exceeds the levels necessary to unambiguously discriminate the covalent modifications of interest from the cation adducts that are typical of mass spectra of nucleic acids. Further, fully resolved isotopic distributions enable the implementation of a data-reduction algorithm, which increases the confidence in the identification of weaker signals provided by probed products and expedites the interpretation of very complex spectra. This aspect is also helped by the preponderant observation in AP MALDI spectra of singly charged species, which contrasts with the multiple overlapping charge states distributions that are typical of mixtures analyzed by electrospray ionization. The application of different nucleases or complementary hydrolysis methods (e.g., alkaline treatment) can afford complete sequence coverage with no loss of information due to products that may exceed the practical size accessible to our analyses. Appropriate selection of hydrolytic procedures and fine tuning of their application can also ensure that 
the size of alkylated oligonucleotides will offer the possibility of sequence confirmation by tandem experiments. Without the implementation of any microspotting method that could greatly improve the overall sensitivity of the technique, the approach based on AP MALDI-FTMS generated a great deal of structural information with a total sample consumption equivalent to an insignificant fraction of the amount necessary to perform either NMR or X-ray crystallography. By expanding to progressively larger RNA substrates, which are expected to provide increasingly complex mixtures of probed/cleaved products, the proposed approach will help to bring mass spectrometry to the forefront of the analytical techniques employed in the structural and functional investigation of RNA and protein-RNA complexes by chemical methods.

\section{Acknowledgments}

The authors thank Dr. V. Doroshenko (MassTech, Inc.) for the use of the AP MALDI source employed in this study and Ms. L. Sapp (Perkin-Elmer, Inc.) for helpful suggestions. S.I.M. is UMBC's Undergraduate Research Scholar for 2003. This work was supported by the National Institutes of Health (R01-GM643208).

\section{References}

1. Tanaka, K.; Ido, H.; Yoshida, Y.; Yoshida, T. Detection of high mass molecules by laser desorption time-of-flight mass spectrometry. Proceedings of the Second Japan-China Joint Symposium on Mass Spectrometry; Osaka, Japan, September 15-18, 1987.

2. Karas, M.; Hillenkamp, F. Laser desorption ionization of proteins with molecular masses exceeding 10,000 Daltons. Anal. Chem. 1988, 60, 2299-2301.

3. Hettich, R.; Buchanan, M. Structural characterization of normal and modified oligonucleotides by matrix-assisted laser desorption Fourier transform mass spectrometry. J. Am. Soc. Mass Spectrom. 1991, 2, 402-412.

4. Nordhoff, E.; Cramer, R.; Karas, M.; Hillenkamp, F.; Kirpekar, F.; Kristiansen, K.; Roepstorff, P. Ion stability of nucleic acids in infrared matrix-assisted laser desorption/ionization mass spectrometry. Nucleic Acids Res. 1993, 21, 3347-3357.

5. Nordhoff, E.; Kirpekar, F.; Roepstorff, P. Mass spectrometry of nucleic acids. Mass Spectrom. Rev. 1996, 15, 67-138.

6. Schneider, K.; Chait, B. T. Matrix-assisted laser desorption mass spectrometry of homopolymer oligodeoxyribonucleotides. Influence of base composition on the mass spectrometric response. Org. Mass Spectrom. 1993, 28, 1353.

7. Kirpekar, F.; Nordhoff, E.; Kristiansen, K.; Roepstorff, P.; Lezius, A.; Hahner, S.; Karas, M.; Hillenkamp, F. Matrix assisted laser desorption/ionization mass spectrometry of enzymatically synthesized RNA up to $150 \mathrm{kDa}$. Nucleic Acids Res. 1994, 22, 3866-3370.

8. Wu, K. J.; Shaler, T. A.; Becker, C. H. Time-of-flight mass spectrometry of underivatized single-stranded DNA oligomers by matrix-assisted laser desorption. Anal. Chem. 1994, 66, 1637-1645.

9. Stemmler, E. A.; Buchanan, M. V.; Hurst, G. B.; Hettich, R. L. Analysis of modified oligonucleotides by matrix-assisted laser desorption/ionization Fourier transform mass spectrometry. Anal. Chem. 1995, 67, 2924-2930.

10. Juhasz, P.; Roskey, M. T.; Smirnov, I. P.; Haff, L. A.; Vestal, M. L.; Martin, S. A. Applications of delayed extraction matrix- assisted laser desorption ionization time-of-flight mass spectrometry to oligonucleotide analysis. Anal. Chem. 1996, 68, 941-946.

11. Talbo, G.; Mann, M. Aspects of the sequencing of carbohydrates and oligonucleotides by matrix-assisted laser desorption/ionization post-source decay. Rapid Commun. Mass Spectrom. 1996, 10, 100-103.

12. Gross, J.; Leisner, A.; Hillenkamp, F.; Hahner, S.; Karas, M.; Schäfer, J.; Lützenkirchen, F.; Nordhoff, E. Investigations of the metastable decay of DNA under ultraviolet matrix-assisted laser desorption/ionization conditions with post-source decay analysis and hydrogen/deuterium exchange. J. Am. Soc. Mass Spectrom. 1998, 9, 866-878.

13. Tang, W.; Zhu, L.; Smith, L. M. Controlling DNA fragmentation in MALDI-MS by chemical modification. Anal. Chem. 1997, 69, 302-312.

14. Nordhoff, E.; Karas, M.; Cramer, R.; Hahner, S.; Hillenkamp, F.; Kirpekar, F.; Lezius, A.; Muth, J.; Meier, C.; Engels, J. W. J. Mass Spectrom. 1995, 30, 99-112.

15. Zhu, L.; Parr, G. R.; Fitzgerald, M. C.; Nelson, C. M.; Smith, L. M. Oligodeoxynucleotide fragmentation in MALDI/TOF mass spectrometry using 355-nm radiation. J. Am. Chem. Soc. 1995, 117, 6048-6056.

16. Hendrickson, C. L.; Emmett, M. R.; Marshall, A. G. Electrospray ionization Fourier transform ion cyclotron resonance mass spectrometry. Annu. Rev. Phys. Chem. 1999, 50, 517-536.

17. Comisarow, M. B.; Marshall, A. G. Fourier transform ion cyclotron resonance. Chem. Phys. Lett. 1974a, 282-283.

18. Cotter, R. J. Time-of-flight mass spectrometry for the structural analysis of biological molecules. Anal. Chem. 1992, 64, 1027A.

19. Cotter, R. J. Time-of-flight mass spectrometry. Instrumentation and applications in biological research; ACS Professional Reference Books: Washington, DC, 1997, pp 169-201.

20. Buchanan, M. V.; Hettich, R. L. Fourier transform mass spectrometry of high-mass biomolecules. Anal. Chem. 1993, 65, 245A-259A.

21. Stemmler, E. A.; Hettich, R. L.; Hurst, G. B.; Buchanan, M. V. Matrix-assisted laser desorption/ionization Fourier-transform mass spectrometry of oligodeoxyribonucleotides. Rapid Commun. Mass Spectrom. 1993, 7, 828-836.

22. Li, Y.; Tang, K.; Little, D. P.; Koster, H.; Hunter, R. L.; McIver, R. T. J. High-resolution MALDI Fourier transform mass spectrometry of oligonucleotides. Anal. Chem. 1996, 68, 2090-2096.

23. Castoro, J. A.; Köster, C.; Wilkins, C. L. Matrix-assisted laser desorption/ionization of high-mass molecules by Fouriertransform mass spectrometry. Rapid Commun. Mass Spectrom. 1992, 6, 239.

24. Köster, C.; Castoro, J. A.; Wilkins, C. L. High-resolution matrix-assisted laser desorption/ionization by Fourier transform mass spectrometry. J. Am. Chem. Soc. 1992, 114, 75727574 .

25. Rempel, D. L.; Gross, M. L. High pressure trapping in Fourier transform mass spectrometry: A radiofrequency-only-mode event. J. Am. Soc. Mass Spectrom. 1992, 3, 590.

26. Schweikhard, L.; Guan, S.; Marshall, A. G. Quadrupolar excitation and collisional cooling for axialization and high pressure trapping of ions in Fourier transform ion cyclotron resonance mass spectrometry. Int. J. Mass Spectrom. Ion Proc. 1992, 120, 71-83.

27. Solouki, T.; Russell, D. H. Laser desorption studies of high mass biomolecules in Fourier-transform ion cyclotron resonance mass spectrometry. Proc. Natl. Acad. Sci. U.S.A. 1992, 89, 5701-5704.

28. Guan, S.; Whal, M. C.; Wood, T. D.; Marshall, A. G. Enhanced mass resolving power, sensitivity, and selectivity in laser desorption Fourier transform ion cyclotron resonance mass 
spectrometry by ion axialization and cooling. Anal. Chem. 1993, 65, 1753.

29. Pasa-Tolic, L.; Huang, S.; Guan, S.; Kim, H. S.; Marshall, A. G. Ultrahigh-resolution matrix-assisted laser desorption/ionization Fourier transform ion cyclotron resonance mass spectra of peptides. J. Mass Spectrom. 1995, 30, 825.

30. Pastor, S. J.; Castoro, J. A.; Wilkins, C. L. High-mass analysis using quadrupolar excitation/ion cooling in a Fourier transform mass spectrometer. Anal. Chem. 1995, 67, 379-384.

31. Yao, J.; Dey, M.; Pastor, S. J.; Wilkins, C. L. Analysis of high-mass biomolecules using electrostatic fields and matrixassisted laser desorption/ionization in a Fourier transform mass spectrometer. Anal. Chem. 1995, 67, 3638-3642.

32. McIver, R. T. J.; Li, Y.; Hunter, R. L. High-resolution laser desorption mass spectrometry of peptides and small proteins, Proc. Natl. Acad. Sci. U.S.A. 1994, 91, 4801-4805.

33. Wu, J.; Fannin, S. T.; Franklin, M. A.; Molinski, T. F.; Lebrilla, C. B. Exact mass determination for elemental analysis of ions produced by matrix-assisted laser desorption. Anal. Chem. $1995,67,3788-3792$.

34. Heeren, R. M.; Boon, J. J. Rapid microscale analyses with an external ion source Fourier transform ion cyclotron resonance mass spectrometer. Int. J. Mass Spectrom. Ion Proc. 1996, 157/158, 391-403.

35. Baykut, G.; Jertz, R.; Witt, M. Matrix-assisted laser desorption/ionization Fourier transform ion cyclotron resonance mass spectrometry with pulsed in-source collision gas and in-source ion accumulation. Rapid Commun. Mass Spectrom. 2000, 14, 1238-1247.

36. O'Connor, P. B.; Costello, C. E. A high pressure matrixassisted laser desorption/ionization Fourier transform mass spectrometry ion source for thermal stabilization of labile biomolecules. Rapid Commun. Mass Spectrom. 2001, 15, 18621868.

37. O'Connor, P. B.; Budnik, B. A.; Ivleva, V. B.; Kaur, P.; Moyer, S. C.; Pittman, J. L.; Costello, C. A. A high pressure matrixassisted laser desorption ion source for Fourier transform mass spectrometry designed to accommodate large targets with diverse surfaces. J. Am. Soc. Mass Spectrom. 2004, 15, $128-132$

38. Krutchinsky, A. N.; Loboda, A. V.; Spicer, V. L.; Dworschak, R.; Ens, W.; Standing, K. G. Orthogonal injection of matrixassisted laser desorption/ionization ions into a time-of -flight spectrometer through a collisional damping interface. Rapid Commun. Mass Spectrom. 1998, 12, 508-518.

39. Laiko, V. V., Burlingame, A. L. U.S. Patent 5965884; 1999.

40. Laiko, V. V.; Baldwin, M. A.; Burlingame, A. L. Atmospheric pressure matrix-assisted laser desorption/ionization mass spectrometry. Anal. Chem. 2000, 72, 652-657.

41. Yamashita, M.; Fenn, J. B. Electrospray ion source. Another variation on the free-jet theme. J. Phys. Chem. 1984, 88, 46714675.

42. Harvey, D. J.; Bateman, R. H.; Bordoli, R.; Tyldesley, R. Ionization and fragmentation of complex glycans with a quadrupole time-of-flight mass spectrometer fitted with a matrix-assisted laser desorption/ionization source. Rapid Commun. Mass Spectrom. 2000, 14, 2135-2142.

43. McLean, J. A.; Russell, W. K.; Russell, D. H. A high repetition rate $(1 \mathrm{kHz})$ microcrystal laser for high throughput atmospheric pressure MALDI-quadrupole time-of-flight mass spectrometry. Anal. Chem. 2003, 75, 648-654.

44. Laiko, V. V.; Moyer, S. C.; Cotter, R. J. Atmospheric pressure MALDI/ion trap mass spectrometry. Anal. Chem. 2000, 72, $5239-5243$.

45. Laiko, V. V.; Taranenko, N. I.; Berkout, V. D.; Musselman, B. D.; Doroshenko, V. M. Atmospheric pressure laser desorp- tion/ionization on porous silicon. Rapid Commun. Mass Spectrom. 2002, 16, 1737-1742.

46. Moyer, S. C.; Cotter, R. J.; Woods, A. S. Fragmentation of phosphopeptides by atmospheric pressure MALDI and ESI/ ion trap mass spectrometry. J. Am. Soc. Mass Spectrom. 2001, 13, 274-283.

47. Galicia, M. C.; Vertes, A.; Callahan, J. H. Atmospheric pressure matrix-assisted laser desorption/ionization in transmission geometry. Anal. Chem. 2002, 74, 1891-1895.

48. Miller, C. A.; Yi, D.; Perkins, P. D. An atmostpheric pressure matrix-assisted laser desorption/ionization ion trap with enhanced sensitivity. Rapid commun. Mass spectrom. 2003, 17, 860-868.

49. Wolfender, J.-L.; Chua, F.; Ball, H.; Wolfender, F.; Fainzilber, M.; Baldwin, M. A.; Burlingame, A. L. Identification of tyrosine sulfation in Conus pennaceus conotoxins $\alpha$-PnIA and $\alpha$ PIB: Further investigation of labile sulfo- and phosphopeptides by electrospray, matrix-assisted laser desorption/ionization (MALDI) mass spectrometry. J. Mass Spectrom. 1999, 34, 447-454.

50. Keough, T.; Lacey, M. P.; Strife, R. J. Atmospheric pressure matrix-assisted laser desorption/ionization ion trap mass spectrometry of sulfonic acid derivatized tryptic peptides. Rapid Commun. Mass Spectrom. 2001, 15, 2227-2239.

51. Creaser, C. S.; Reynolds, J. C.; Harvey, D. J. Structural analysis of oligosaccharides by atmospheric pressure matrix-assisted laser desorption/ionization quadrupole ion trap mass spectrometry. Rapid Commun. Mass Spectrom. 2002, 16, 176-184.

52. Madonna, A. J.; Voorhees, K. J. Detection of cyclic lipopeptide biomarkers from Bacillus species using atmospheric pressure matrix-assisted laser desorption/ionization mass spectrometry. Anal. Chem. 2003, 75, 1628-1637.

53. Kellersberger, K. A.; Tan, P. V.; Laiko, V. V.; Doroshenko, V. M.; Fabris, D. Atmospheric pressure MALDI-Fourier transform mass spectrometry. Anal. Chem. 2004, 66, 3930-3934.

54. Yu, E.; Fabris, D. Direct probing of RNA structures and RNA-protein interactions in the HIV-1 packaging signal by chemical modification and electrospray ionization Fourier transform mass spectrometry. J. Mol. Biol. 2003, 330, 211-223.

55. Doroshenko, V. M.; Laiko, V. V.; Taranenko, N. I.; Berkhout, V. D.; Lee, H. S. Recent developments in atmospheric pressure MALDI mass spectrometry. Int. J. Mass Spectrom. Ion Proc. 2002, 221, 39-58.

56. Moyer, S. C.; Marzilli, L. A.; Woods, A. S.; Laiko, V. V.; Doroshenko, V. M.; Cotter, R. J. Atmospheric pressure matrixassisted laser desorption/ionization (AP MALDI) on a quadrupole ion trap mass spectrometer. Int. J. Mass Spectrom. Ion Proc. 2003, 226, 133-150.

57. Tan, P. V.; Laiko, V. V.; Doroshenko, V. M. Atmospheric pressure MALDI with pulsed dynamic focusing for highefficiency transmission of ions into a mass spectrometer. Anal. Chem. 2004, 75, 2462-2469.

58. Sannes-Lowery, K.; Griffey, R. H.; Kruppa, G. H.; Speir, J. P.; Hofstadler, S. A. Multipole storage assisted dissociation, a novel in-source dissociation technique for electrospray ionization generated ions. Rapid Commun. Mass Spectrom. 1998, 12, 1957-1961.

59. de Koning, L. J.; Nibbering, N. M. M.; van Orden, S. L.; Laukien, F. H. Mass selection of ions in a Fourier transform ion cyclotron resonance trap using correlated harmonic excitation fields (CHEF). Int. J. Mass Spectrom. Ion Proc. 1997, 165/166, 209-219.

60. Gauthier, J. W.; Trautman, T. R.; Jacobson, D. B. Sustained off-resonance irradiation for collision-activated dissociation involving Fourier transform mass spectrometry. Collision- 
activated dissociation technique that emulates infrared multiphoton dissociation. Anal. Chim. Acta 1991, 246, 211-225.

61. Kim, Y.; Hurst, G. B.; Doktycz, M. J.; Buchanan, M. V. Improving spot homogeneity by using polymer substrates in matrix-assisted laser desorption/ionization mass spectrometry of oligonucleotides. Anal. Chem. 2001, 73, 2617-2624.

62. Smirnov, I. P.; Hall, L. R.; Ross, P. L.; Haff, L. A. Applications of DNA-binding polymers for preparation of DNA for analysis by matrix-assisted laser desorption/ionization mass spectrometry. Rapid Commun. Mass Spectrom. 2001, 15, 1427-1432.

63. Xu, Y.; Bruening, M. L.; Watson, J. T. Use of polymer-modified MALDI-MS probes to improve analyses of protein digests and DNA. Anal. Chem. 2004, 76, 3106-3111.

64. Pieles, U.; Zurcher, W.; Schar, M.; Moser, H. E. Matrix-assisted laser desorption ionization time-of-flight mass spectrometry: a powerful tool for the mass and sequence analysis of natural and modified oligonucleotides. Nucleic Acids Res. 1993, 21, 3191-3196.
65. Little, D. P.; Cornish, T. J.; O’Donnell, M. J.; Braun, A.; Cotter, R. J.; Köster, H. MALDI on a chip; Analysis of arrays of low-femtomole to subfemtomole quantities of synthetic oligonucleotides and DNA diagnostic products dispensed by a piezoelectric pipet. Anal. Chem. 1997, 69, 4540-4546.

66. Xu, Y.; Watson, J. T.; Bruening, M. L. Patterned monolayer/ polymer films for analysis of dilute or salt-contaminated protein samples by MALDI-MS. Anal. Chem. 2003, 75, 185-190.

67. Batey, R. T.; Rambo, R. P.; Doudna, J. A. Tertiary motifs in RNA structure and folding. Angew. Chem. Int. Ed. Engl. 1999, $38,2326-2343$.

68. Kellersberger, K. A.; Yu, E.; Kruppa, G. H.; Young, M. M.; Fabris, D. Top-down characterization of nucleic acids modified by structural probes using high-resolution tandem mass spectrometry and automated data interpretation. Anal. Chem. 2004, 76, 2438-2445.

69. Yu, T. E.; Zhang, Q.; Fabris, D. Untying the FIV frameshifting pseudoknot structure by MS3D. J. Mol. Biol. 2005, 345, 69-80. 